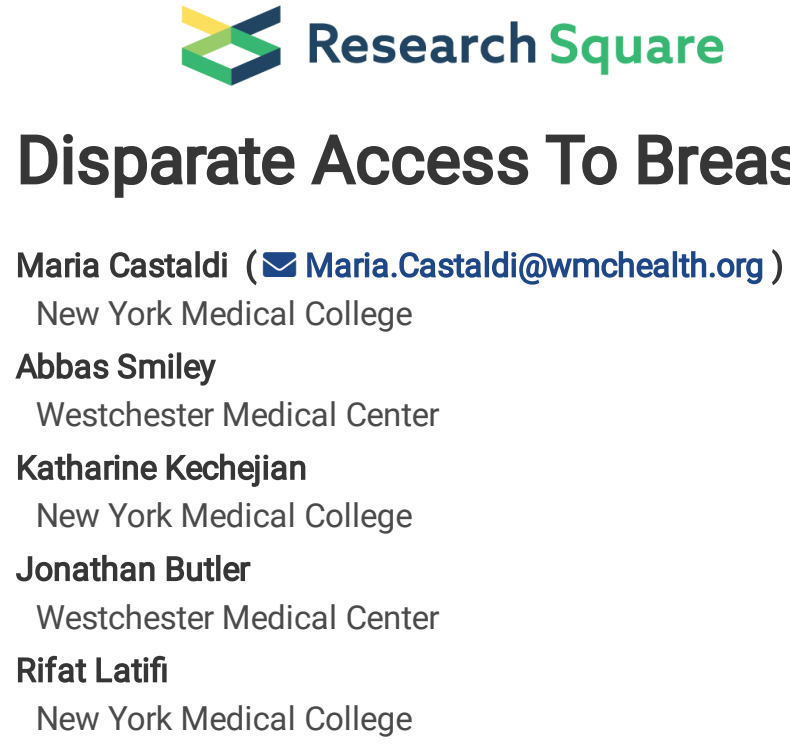

Maria Castaldi ( Maria.Castaldi@wmchealth.org)

New York Medical College

Abbas Smiley

Westchester Medical Center

Katharine Kechejian

New York Medical College

Jonathan Butler

Westchester Medical Center

Rifat Latifi

New York Medical College

\title{
Disparate Access To Breast Cancer Screening And Treatment
}

\section{Research Article}

Keywords: breast cancer, patient navigation programs, mammography, diagnostic

Posted Date: June 21st, 2021

DOI: https://doi.org/10.21203/rs.3.rs-574141/v1

License: (-) (i) This work is licensed under a Creative Commons Attribution 4.0 International License. Read Full License 


\section{Abstract}

Background: Barriers to breast cancer screening remain despite Medicaid expansion for preventive screening tests and implementation of patient navigation programs (PNP) under the Affordable Care Act. Women from underserved communities experience disproportionately low rates of screening mammography. This study compares barriers to breast cancer screening among women at an inner-city safety-net center (City) and those at a suburban county medical center (County). Inner city and suburban county medical centers' initiatives were studied to compare outcomes of breast cancer screening and factors that influence access to care.

Methods: Women 40 years of age or older delinquent in breast cancer screening were offered PN services between October 2014 and September 2019. Four different screening time-to-event intervals were investigated: time from PN acceptance to screening mammography, to diagnostic mammography, to biopsy, and overall screening completion time. Barriers to complete breast cancer screening between the two centers were compared.

Results: Women from lowest income quartiles took significantly longer to complete breast cancer screening when compared to women from higher income quartiles when a barrier was present, regardless of barrier type and center. Transportation was a major barrier to screening mammography completion, while fear was the major barrier to abnormal screening work up. Table 1 .

Conclusion: Disparity in breast cancer screening and management persists despite implementation of a PNP. In the presence of a barrier, women from the lowest income quartiles have prolonged breast cancer screening completion time regardless of center or barrier type. Women who experience fear have longest screening time completion. Future directions aim to increase resource allocation to ameliorate wait times in overburdened safety-net hospitals as well as advanced training for PN to alleviate women's fears.

\section{Introduction}

Under the Affordable Care Act, Medicaid in New York was expanded in 2014. Medicaid expansion allowed insurance coverage for screening mammography. Expanded eligibility by acquiring insurance improves access to preventative care ${ }^{1}$. The increase in Medicaid coverage allowed improved access to screening mammography in women from low-income groups. It has been shown that when offered services, communities that would otherwise have difficulty obtaining screening studies, do take advantage of expanded opportunities via programs provided by the state that have led to improved access to breast health and screening mammography ${ }^{2}$.

Governor Andrew M. Cuomo launched 'Get Screened, No Excuses' campaign to increase mammographic screening rates in New York ${ }^{3}$. The governor's project provided funding for patient navigation (PN) services with the goal to increase the number of women screened for breast cancer and offer support and assistance for follow through with screening and associated diagnostics and treatment as needed. Prior analysis of breast centers' initiatives and outcomes on breast cancer screening rates supported by the New York State Patient Navigation Program (PNP) for Breast Cancer Screening showed that age, screening stage, and income were the most important variables associated with compliant breast cancer screening ${ }^{2}$. PN captured women delinquent in breast cancer screening and increased screening by 800 women per year. However, despite implementation of the governor's PNP, disparate screening rates persisted in those treated at safety-net hospital with lower socioeconomic status (SES) as it related to timeliness of care. Further, despite navigation implementation in safety net-hospitals, barriers remained that could not be overcome to improve timeliness to screening. Poorer outcomes and mortality will continue to rise due to disparate treatment rates. The authors sought to investigate barriers that could be responsible for disparate timely completion of breast cancer screening in women of lower SES. This investigation would serve to better understand how to improve healthcare delivery and preventative measures to patients cared for in centers serving lower income populations.

Women from underserved populations are least likely to be screened for many reasons. Through the provisions of the governor's New York State Department of Health grant, centers were awarded funding to support activities related to the grant's breast cancer initiatives in providing screening patient navigation to women in need of breast cancer screening. Two centers identified similar target populations to increase breast cancer screening in those delinquent in screening. Both centers serve uninsured and Medicaid populations who are in greatest need of the barrier reduction support that patient navigation provides. The breast program leaders developed similar pathways for grant project delivery; one center is a safety-net hospital and the second, a county medical center. 


\section{Methods}

\section{Data Source:}

Institutional data was collected from two breast centers accredited by the American College of Surgeons' National Accreditation Program for Breast Centers (NAPBC) in receipt of funding from the governor's grant for the New York State Patient Navigation Program for Breast Cancer Screening. We compare an inner-city safety net hospital (City), serving mainly patients who are socioeconomically disadvantaged and underrepresented and a second center (County), a regional suburban county hospital, serving patients who are more socioeconomically advantaged, but may still contain marginalized and underrepresented communities. Women 40 years of age or older delinquent in breast cancer screening one year or greater were eligible for enrollment and PN services.

A PN data tracker followed women who accepted PN services for breast cancer screening through the governor's grant at both centers. Women accepted PN services at initial encounter between patient and navigator, in person or by telephone. In person encounters occurred at screening and outreach events. The tracking tool included demographic information as well as barriers present or encountered that interfered with ability to obtain a mammogram. The PN recorded patient self-reported barriers to screening on the tracking tool.

Process measures monitored included numbers of women contacted within the health care centers and from the priority communities with the offer of PN services, individuals referred for screening mammography, individuals in need of screening, total women screened, total women with positive findings and requiring breast biopsy. The NYS DOH/Health Research Inc. ${ }^{4}$ staff monitored the progress of the City and County contractor's progress towards work plan goals, objectives, and deliverables to meet funding criteria. Project progress and screening results were generated monthly, quarterly, semiannually, and reported to $\mathrm{DOH}$.

Target and priority populations for community outreach activity were identified by collaborating with off- site community centers and local health systems, DSRIP Program Performing Provider Systems, Federally Qualified Health Centers (FQHCs), and health plans. Hospital radiology logs of missed appointments also identified those in need of breast screening. Patient Navigators (PNs) contacted those patients referred by community partners and from lists generated by affiliated health systems and radiology logs in order to determine need for and overdue breast cancer screening. PNs identified those in need of breast cancer screening and acceptance of PN services, the PNs addressed barriers, scheduled for cancer screening services, followed up to ensure screening completion and connection with follow up resources, including hand off to the NAPBC navigator when abnormal findings were identified on mammography. Barrier assessment tools were created and used by each institution. The barriers assessed were grouped into child care; paid time off (PTO); transportation; fear, which combined fear of procedure, and fear of results; support, which combined family support, support for cultural barriers, support for religious barriers, companion to accompany; scheduling, which combined assistance scheduling appointment, missed appointment, and scheduling conflicts; and other, which included all remaining barriers such as immigration concerns, insurance concerns, and language barriers. The governor's grant PN activity was integrated into the program's current NAPBC education and outreach activity workflow requirement to maintain American College of Surgeon's NAPBC accreditation.

\section{Patient Selection:}

Women 40 years of age or older delinquent in breast cancer screening one year or greater were offered PN services. Those who accepted and completed breast cancer screening at one of two, City or County, NAPBC-accredited breast centers between October 2014 and September 2019 were tracked. Our primary outcomes of interest were identification of barriers to care.

\section{Statistical Analyses:}

Comparative analysis on women aged 40 years and over in need of screening mammography who accepted PN services at City and County NAPBC-accredited breast centers was conducted. Frequency distribution of different barriers was compared between those who completed the study and those who did not, using chi-square test. Similarly, the frequency distribution of different barriers was compared between the two centers using chi-square test. Differences in breast cancer screening times were compared between the two centers for each barrier using $t$ test. Additionally, differences in breast cancer screening times were compared among various barriers within each center using ANOVA. Women were classified according to income quartiles. Screening times were compared among various barriers within each income quartile using ANOVA. The prevalence of barriers within each stage of screening were 
compared using chi-square test. An alpha level of 0.05 was used to determine if the groups were statistically different. Data was analyzed using SPSS, version 26 (IBM Corporation, SPSS, Chicago, IL

\section{Results}

The sample contained 2,505 women aged 40 years or older who accepted PN services between October 2014 and September 2019. Mean (SD) age of patients was 56.2 (10) years. City center included $38 \%$ of total sample size and County center $62 \%$.

\section{BARRIERS TO BREAST CANCER SCREENING}

Of the 2,505 women included in the study, $39.6 \%$ identified no barrier to breast screening. The most common barriers were transportation (21.8\%), no PTO (18.3\%), and childcare (11.5\%). Results are presented in the appendix.

\section{BARRIER PRESENCE AND COMPLETION OF SCREENING}

Among women who identified no barrier to breast cancer screening, $42.5 \%$ completed the screening, which was similar to the percentage of women who initially identified no barrier to screening (39.6\%). Of the women who identified transportation as a barrier, $27.9 \%$ did not complete the screening, indicating that transportation was the most common barrier that prevented completion of breast cancer screening among city and county women, regardless of income quartile. Results can be found in Table 1.

Table 1

Barrier Presence and Completion of Screening, All Patients.

\begin{tabular}{|llll|}
\hline Barrier & Not Screened, N (\%) & Completed Screening, N (\%) & p-value \\
\hline No Barrier & $52(17.5 \%)$ & $939(42.5)$ & $<0.001$ \\
\hline Child Care & $48(16.2 \%)$ & $241(10.9)$ & $\mathbf{0 . 0 0 8}$ \\
\hline No PTO & $68(22.9 \%)$ & $390(17.7 \%)$ & $\mathbf{0 . 0 2 9}$ \\
\hline Transportation & $83(27.9 \%)$ & $464(21.0 \%)$ & $\mathbf{0 . 0 0 7}$ \\
\hline Fear & $30(10.1 \%)$ & $122(5.5 \%)$ & $\mathbf{0 . 0 0 2}$ \\
\hline Support & $4(1.3 \%)$ & $21(1.0 \%)$ & 0.528 \\
\hline Schedule & $3(1.0 \%)$ & $11(0.5 \%)$ & 0.226 \\
\hline Other & $9(3.0 \%)$ & $20(0.9 \%)$ & 0.001 \\
\hline
\end{tabular}

SCREENING COMPLETION BY TYPE OF BARRIER AND CENTER VISITED

There was a significant difference between the percentage of women in City and County centers who experienced no barrier and completed the breast cancer screening (Table 2). City women identified no PTO and transportation as the most common barriers to screening completion compared to County women (Table 2). Thus, more than $58 \%$ of City women experienced no PTO and transportation as barriers to completion of screening, compared to approximately $25 \%$ of County women who faced the same barriers. More City women experienced childcare as a barrier than county women (Table 2). Regardless of the barrier present, there was no significant difference between the percentage of women at City and County centers who did not complete breast cancer screening (Table 2). 
Table 2

Screening Completion by Type of Barrier and Center

\begin{tabular}{|lllllll|}
\hline & \multicolumn{3}{l}{ Completed Screening, N (\%) } & \multicolumn{4}{c|}{ Did Not Complete Screening, N (\%) } \\
\hline Barrier & City & County & p-value & City & County & p-value \\
\hline No Barrier & $83(9.2 \%)$ & $856(65.4 \%)$ & $<0.001$ & $44(16.5 \%)$ & $8(26.7 \%)$ & 0.164 \\
\hline Child Care & $146(16.2 \%)$ & $95(7.3 \%)$ & $<0.001$ & $44(16.5 \%)$ & $4(13.3 \%)$ & 0.798 \\
\hline No PTO & $228(25.3 \%)$ & $162(12.4 \%)$ & $<0.001$ & $59(22.1 \%)$ & $9(30.0 \%)$ & 0.329 \\
\hline Transportation & $298(33.1 \%)$ & $166(12.7 \%)$ & $<0.001$ & $76(28.5 \%)$ & $7(23.3 \%)$ & 0.553 \\
\hline Fear & $119(13.2 \%)$ & $3(0.2 \%)$ & $<0.001$ & $30(11.2 \%)$ & $0(0 \%)$ & 0.055 \\
\hline Support & $2(0.2 \%)$ & $19(1.5 \%)$ & 0.003 & $2(0.7 \%)$ & $2(6.7 \%)$ & 0.052 \\
\hline Schedule & $11(1.2 \%)$ & $0(0 \%)$ & $<0.001$ & $3(1.1 \%)$ & $0(0 \%)$ & 0.999 \\
\hline Other & $13(1.4 \%)$ & $7(0.5 \%)$ & 0.027 & $9(3.4 \%)$ & $0(0 \%)$ & 0.606 \\
\hline
\end{tabular}

AVERAGE SCREENING TIME COMPLETION BY BARRIER TYPE AND CENTER VISITED

An ANOVA test was performed to compare average breast cancer screening time completion by barrier type within each center (Table 3). In the City center, women who experienced fear as a barrier had the longest screening time completion (41.92 days), and women who experienced no PTO as a barrier had the shortest screening time completion (25.59 days). Significant difference was observed in terms of prevalence of different barriers among women in the City (Table 3). In the County center, women who noted childcare as a barrier had the longest screening time completion (20.57 days), and women who experienced other barriers had the shortest screening time completion (5.00 days). There was no significant difference in terms of prevalence of different barriers among County women (Table 3). In addition, a t-test was performed to compare average breast cancer screening time completion by barrier type between the two centers (Table 3). When comparing the two centers, only two barriers, no PTO and transportation, led to significantly longer completion times in City compared to County across all income quartiles ( 25.69 days vs. 15.76 days, 28.77 days vs. 13.66 days, respectively).

Table 3

Average Screening Time Completion by Barrier Type and Center

\begin{tabular}{|c|c|c|c|c|c|c|c|}
\hline \multirow[t]{2}{*}{ Barrier } & \multicolumn{3}{|l|}{ City Center } & \multicolumn{4}{|c|}{ County Center } \\
\hline & $\mathbf{N}$ & Mean (SD) & p-value* & $\mathbf{N}$ & Mean (SD) & p-value* & p-value ${ }^{* *}$ \\
\hline No Barrier & $83(9.2 \%)$ & 31.85 (61.77) & \multirow[t]{8}{*}{0.041} & $856(65.4 \%)$ & $17.37(39.43)$ & \multirow[t]{8}{*}{0.641} & 0.050 \\
\hline Child Care & $146(16.2 \%)$ & $32.33(54.63)$ & & 95 (7.3\%) & $20.57(41.52)$ & & 0.060 \\
\hline No PTO & $228(25.3 \%)$ & $25.69(46.67)$ & & $162(12.4 \%)$ & $15.76(28.69)$ & & 0.010 \\
\hline Transportation & $298(33.1 \%)$ & 28.77 (51.08) & & $166(12.7 \%)$ & $13.66(28.08)$ & & $<0.001$ \\
\hline Fear & $119(13.2 \%)$ & 41.92 (63.99) & & $3(0.2 \%)$ & $6.00(5.29)$ & & 0.132 \\
\hline Support & $2(0.2 \%)$ & $126.50(74.25)$ & & 19 (1.5\%) & $9.58(15.29)$ & & 0.267 \\
\hline Schedule & $11(1.2 \%)$ & 41.27 (37.36) & & $0(0 \%)$ & & & \\
\hline Other & $13(1.4 \%)$ & 31.08 (27.35) & & $7(0.5 \%)$ & $5.00(1.73)$ & & 0.005 \\
\hline
\end{tabular}

AVERAGE SCREENING COMPLETION TIME BY BARRIER TYPE AND INCOME QUARTILE

ANOVA was performed to compare the average screening completion time by barrier type within each income quartile (Table 4). Within income quartile 1, there was no difference in mean time of screening completion according to different barriers. Within income quartile 2, there was a significant difference in mean time of screening completion according to different barriers. The longest time of screening completion was associated with childcare (56.91 days) and transportation (20.33 days). Within income quartile 3 , there was no difference in mean time of screening completion according to different barriers (Table 4). Within income quartile 4, there was 
a significant difference in mean time of screening completion according to different barriers. The longest time of screening completion was associated with no barrier (28.75 days) and childcare (20.19 days).

Table 4

Average Screening Completion Time by Barrier Type and Income Quartile.

\begin{tabular}{|c|c|c|c|c|c|c|c|c|c|c|c|c|c|}
\hline \multirow[t]{2}{*}{ Barrier } & \multicolumn{3}{|c|}{ Income Quartile 1} & \multicolumn{3}{|c|}{ Income Quartile 2} & \multicolumn{3}{|c|}{ Income Quartile 3} & \multicolumn{3}{|c|}{ Income Quartile 4} & \multirow{2}{*}{$\begin{array}{l}\mathrm{p}- \\
\text { value }\end{array}$} \\
\hline & $\mathbf{N}$ & $\begin{array}{l}\text { Mean } \\
\text { (SD) }\end{array}$ & $\mathbf{P}$ & $\mathbf{N}$ & $\begin{array}{l}\text { Mean } \\
\text { (SD) }\end{array}$ & $\mathbf{P}$ & $\mathbf{N}$ & $\begin{array}{l}\text { Mean } \\
\text { (SD) }\end{array}$ & $\mathbf{P}$ & $\mathbf{N}$ & $\begin{array}{l}\text { Mean } \\
\text { (SD) }\end{array}$ & $\mathbf{P}$ & \\
\hline No Barrier & 50 & $\begin{array}{l}30.24 \\
(51.80)\end{array}$ & 0.1 & 516 & $\begin{array}{l}10.08 \\
(33.76)\end{array}$ & 0.001 & 77 & $\begin{array}{l}33.14 \\
(57.75)\end{array}$ & 0.07 & 263 & $\begin{array}{l}28.75 \\
(44.87)\end{array}$ & 0.002 & $\begin{array}{l}< \\
0.001\end{array}$ \\
\hline Child Care & 81 & $\begin{array}{l}43.69 \\
(67.34)\end{array}$ & & 11 & $\begin{array}{l}56.91 \\
(92.78)\end{array}$ & & 87 & $\begin{array}{l}14.45 \\
(22.25)\end{array}$ & & 62 & $\begin{array}{l}20.19 \\
(32.05)\end{array}$ & & $\begin{array}{l}<.001 \\
0.001\end{array}$ \\
\hline No PTO & 116 & $\begin{array}{l}29.16 \\
(47.53)\end{array}$ & & 24 & $\begin{array}{l}14.29 \\
(20.97)\end{array}$ & & 126 & $\begin{array}{l}21.47 \\
(44.68)\end{array}$ & & 124 & $\begin{array}{l}15.96 \\
(29.22)\end{array}$ & & 0.06 \\
\hline Transportation & 165 & $\begin{array}{l}27.62 \\
(46.181)\end{array}$ & & 27 & $\begin{array}{l}20.33 \\
(33.14)\end{array}$ & & 143 & $\begin{array}{l}26.55 \\
(24.40)\end{array}$ & & 129 & $\begin{array}{l}15.03 \\
(30.29)\end{array}$ & & 0.07 \\
\hline Fear & 69 & $\begin{array}{l}46.06 \\
(65.93)\end{array}$ & & 4 & $\begin{array}{l}17.75 \\
(23.27)\end{array}$ & & 43 & $\begin{array}{l}38.35 \\
(64.07)\end{array}$ & & 4 & $\begin{array}{l}6.25 \\
(4.03)\end{array}$ & & 0.52 \\
\hline Support & & & & & & & 9 & $\begin{array}{l}40.89 \\
(59.08)\end{array}$ & & 12 & $\begin{array}{l}5.58 \\
(3.32)\end{array}$ & & 0.05 \\
\hline Schedule & 3 & $\begin{array}{l}30.67 \\
(29.57)\end{array}$ & & 1 & $3.00(-)$ & & 7 & $\begin{array}{l}51.29 \\
(40.22)\end{array}$ & & & & & 0.45 \\
\hline Other & 7 & $\begin{array}{l}30.86 \\
(32.07)\end{array}$ & & & & & 7 & $\begin{array}{l}27.43 \\
(23.97)\end{array}$ & & 6 & $\begin{array}{l}5.17 \\
(1.84)\end{array}$ & & 0.14 \\
\hline
\end{tabular}

BARRIER PRESENCE AND BREAST CANCER SCREENING STAGE

There were major differences when analyzing prevalence of barrier presence within each stage of screening (Table 5). Transportation and no PTO were the major barriers to completing screening mammography (27.9\% and $22.9 \%$ ). Fear also posed a barrier to screening mammography (10.1\%). Of the patients who completed screening mammography, $21.0 \%$ still experienced transportation as a barrier. On the other hand, a higher percentage of women did not complete diagnostic mammography when fear was present (23.5\%). Fear was the barrier that played a major role in determining who completed diagnostic mammography (Table 5). For those women requiring diagnostic mammograms, the only difference between those who completed and those who did not complete this stage was presence of fear as a barrier. One quarter of patients did not complete diagnostic mammography based on fear alone.

Table 5

Barrier Presence and Breast Screening Stage.

\begin{tabular}{|lllllll|}
\hline \multicolumn{5}{|l}{ Completed Screening Mammography } & \multicolumn{3}{c|}{ Completed Diagnostic Mammography } \\
\hline Barrier & No, N (\%) & Yes, N (\%) & p-value & No, N (\%) & Yes, N (\%) & p-value \\
\hline No Barrier & $52(17.5 \%)$ & $939(42.5)$ & $<0.001$ & $6(17.6 \%)$ & $46(24.7 \%)$ & 0.371 \\
\hline Child Care & $48(16.2 \%)$ & $241(10.9)$ & 0.008 & $6(17.6 \%)$ & $31(16.7 \%)$ & 0.888 \\
\hline No PTO & $68(22.9 \%)$ & $390(17.7 \%)$ & 0.029 & $5(14.7 \%)$ & $36(19.4 \%)$ & 0.522 \\
\hline Transportation & $83(27.9 \%)$ & $464(21.0 \%)$ & 0.007 & $9(26.5 \%)$ & $44(23.7 \%)$ & 0.724 \\
\hline Fear & $30(10.1 \%)$ & $122(5.5 \%)$ & 0.002 & $8(23.5 \%)$ & $20(10.8 \%)$ & 0.040 \\
\hline Support & $4(1.3 \%)$ & $21(1.0 \%)$ & 0.528 & $0(0 \%)$ & $2(1.1 \%)$ & 0.999 \\
\hline Schedule & $3(1.0 \%)$ & $11(0.5 \%)$ & 0.226 & $0(0 \%)$ & $1(0.5 \%)$ & 0.999 \\
\hline Other & $9(3.0 \%)$ & $20(0.9 \%)$ & 0.001 & $0(0 \%)$ & $6(3.2 \%)$ & 0.594 \\
\hline
\end{tabular}


In terms of completion of screening mammography, several barriers are significant, including transportation, 25\%; PTO, 25\%; in addition to fear, which precluded timely completion. $21 \%$ of those who completed the screening mammogram mentioned transportation as the main barrier compared to $28 \%$ of those who did not complete screening. In other words, one fifth of the population who actually completed the study also mentioned transportation as a barrier.

\section{Discussion}

Our study revealed that women with lower SES status had longer completion times for each breast cancer screening stage as well as a longer overall completion times compared to women with higher SES. Among City women, fear was the most prominent and prohibitive barrier to obtain screening mammography. However, between City and County, transportation and no paid time off were the most significant barriers to timely access to breast cancer screening barriers.

The authors delineated differences between inner city and suburban populations in prior investigations ${ }^{2}$. We further explore and describe the reasons for significant differences between the populations. Patients in lower income quartiles have been shown to have lower breast cancer-specific survival, as they have lower use of mammography and present at later stages of breast cancer compared with those in higher social classes ${ }^{5}$. Our study found that once women utilized the centers' PNP for breast care, there was no difference in time to complete the screening phases among different income quartiles at each center. Therefore, the barriers that women in low-income quartiles face in initially seeking preventive medical care play a major role in timeliness to care. It has been shown that women of low SES face financial barriers such as loss of wages for medical care visits as well as medical care system barriers, such as poor understanding of necessity of screening or fear of screening procedure or results, compared to more compliant women ${ }^{6}$. However, once women were connected to breast health services via patient navigation program, timeliness to care was not significantly different across income quartiles in both City and County centers.

When comparing timeliness of screening study completion between City and County centers, County women completed the screening process in almost half the time as City women. The shortest times to screening completions in the City center were still greater than the longest time interval in County center. This finding highlights that timeliness to care is influenced by where patients seek medical care and the quality of care that they receive. Safety-net hospitals offer health services to low-income populations and uninsured, and are generally located in large metropolitan areas ${ }^{7}$. Often, safety-net hospitals have fewer resources and are more financially burdened than non-safety-net hospitals ${ }^{8,9}$. Hospitals with high percentages of Medicaid patients, such as safety-net hospitals, are more likely to sustain financial burden. Medicare and Medicaid often reimburse less than private insurance companies for similar services, thus compounding financial deficit as the majority of Medicaid patients are treated in the public hospital system ${ }^{5}$. Nonetheless, quality programs such as the NAPBC prompt institutions to strive for quality measures.

Research highlights underuse of cancer therapies among poorer communities ${ }^{10}$. This finding has been attributed centers' struggle with organizational strategies to track and guide patients. This, in turn, greatly affects the overall time to complete breast cancer screening processes. Safety-net hospitals are experiencing an increase in caseload and wait times, as well as a shortage of support staff which can slow the delivery of care to patients ${ }^{11,12}$. In turn, this may add to patient anxiety, gaps in care, and perhaps worse survival outcomes due to delayed care ${ }^{11,13,14}$. These system level differences may partially explain racial, ethnic and socioeconomic disparities in breast cancer prognosis.

Our major finding from Table 2, shows over half of City women experienced no PTO and transportation as barriers to completion of screening, compared to one fourth of County women who faced the same barriers. City women also experienced childcare as a barrier more often than County women. Thus, in addition to center differences, place of residence may play a role in access to health services and breast cancer risk or mortality ${ }^{15}$. Patients living communities with lower numbers of mammography facilities per female population, inadequate mammography capacity, staff shortages, or limited availability of evening and weekend hours have been associated with a lower likelihood of breast cancer screenings and longer wait times for screening appointments ${ }^{5,16}$. Women struggle to keep appointments when they live far from the nearest screening facility or lack transportation ${ }^{16,17}$. The high concentration of vulnerable populations and economically disadvantaged areas in a city setting may explain why urban women are more likely to present with late-stage disease than those who live in suburban and rural areas ${ }^{18,19}$. These women who sought care at the inner-city urban center based on place of residence experienced prolonged screening stage times as well as overall completion time due to the barriers described above. 
Fear poses a major barrier to breast cancer screening completion. In the City center, women who experienced fear as a barrier had the longest screening time completion. The only difference between women who completed the required diagnostic mammogram and those who did not complete this stage was the presence of fear as a barrier. One quarter of patients did not complete diagnostic mammography based on fear alone. Minority populations receiving health care in urban settings may experience poorer outcomes as their cultural attitudes and belief systems surrounding the health care system delay seeking care $e^{5,20,21}$. It has been shown that psychosocial factors such as fear and anxiety, fatalistic attitudes, perceived risk, misunderstanding, the competing demands of caring for others, and social norms may delay diagnostic assessment and treatment in this subgroup ${ }^{20}$. Further, compared to urban women, rural women were more likely to believe mammography would find small breast lesions early and strongly disagreed that mammography was embarrassing or that they were afraid of an abnormal finding ${ }^{22}$. Women in the City center are more ethnically and racially diverse when compared to women in the County center. As such, these factors may play a role in breast cancer screening outcomes between the two populations. When comparing characteristics of urban and suburban populations, urban areas are more racially and ethnically diverse, as nonwhites make up the majority of the population, while suburban and rural areas are predominantly white ${ }^{18}$.

We also found that women from the lowest SES quartiles took significantly longer to complete each screening stage as well as the total completion time compared to women from the highest quartile when a barrier was present. Regardless of the type of barrier present, women from the highest income quartile completed screening faster than women from the lowest income quartile. This outcome indicates that low SES women continue to face disparate access and treatment beyond the barriers that they face. This is due to less resources to overcome barriers as well as overburdened centers serving poorer communities ${ }^{5,11,16,17}$. Key barriers to accessing cancer services are related to older age, co-morbidities, minority race, and low SES ${ }^{5,13}$. Based on our findings, County women were significantly older with higher SES compared with women from the City center. We found that income, age, and screening stage were the most important variables associated with time to completion for breast cancer screening. Older age is a significant factor in treatment delays, which suggests that an increased number of comorbidities may be associated with longer wait times $^{13,23}$. However, in contrast, we found that women were older in the County center and had faster screening times compared to younger women in the City center. This suggests that there were other factors influencing breast cancer screening outcomes among our patient population in the City center. Perhaps older women with understanding of importance of early detection and will prioritize and utilize screening benefits. Patients receiving care at hospitals serving predominantly minority populations tend to have worse outcomes than those treated at nonminority serving institutions, and vulnerable populations tend to get their care at safety-net hospitals ${ }^{12,23-26}$.

In our study, the most common barriers were the same across the four income quartiles: transportation, childcare, and no paid time off (PTO). This is concurrent with the literature reports showing transportation to be the biggest barrier in general ${ }^{27,28}$, and in underserved women barriers such as fear of cost, fear of mammogram-associated pain and fear of getting bad news are most common ${ }^{29,30}$. Having insurance was found to be associated with perceiving fear of both mammogram-related pain and receiving bad news as barriers, rather than perceiving cost as a barrier ${ }^{29}$. Despite free services, underserved women continue to report experiential and psychological obstacles to mammography, suggesting the need for improved targeted education and outreach in this population ${ }^{29}$. Despite patient navigation, education of navigator as well as patient should be further studied. Further, among minority women, the most common barriers noted were pain and embarrassment associated with screening mammography, lack of health insurance, poor knowledge about breast cancer screening, lack of physician recommendation, lack of trust in hospitals and doctors, language barriers and lack of transportation ${ }^{27}$. Non-compliant women more likely to report barriers to follow up, such as cost of loss wages and medical care system barriers, or fears, than compliant women ${ }^{6}$. In addition, living in a socioeconomically deprived area with high unemployment rates and crime forces day-to-day survival with less time and attention to preventative care. Lower cancer screening rates or advanced stages of breast cancer at diagnosis do occur in marginalized populations for the reasons described above ${ }^{6}$.

Future directions should target education for those that navigate. It is well known that PNP enhance system throughput for breast cancer treatment ${ }^{31}$. However, what is less known are the effects of navigation training and education levels and effects on care enhancement ${ }^{31}$. Patient fear toward the screening procedure and the uncertainties about the results of screening seem to be the strongest influence in decisions to pursue screening. Heath care providers and patient navigators must gain a better understanding of fear from the patient's perspective, in order to address this barrier. Motivation to overcome fears relies on how passionately 
physicians and patient navigators advocate for breast screening. Both physicians and patient navigators should express the importance of screening while understanding that many patients may need to reach a level of comfort before they agree to be screened. Education in areas such as cultural competency may aid in addressing common barriers as fear.

\section{Limitations}

There were several limitations of this study. First, structural barriers were present. Patients who were unable to make timely appointments due to overbooked mammogram schedules and lack of staff to support screening off hours such as weekends or nights were not tracked. Second, factors influencing physician recommendations were not controlled for in this study. It was difficult to gather data on the physician's recommendations for patients in order to determine if in fact some patients were following USTPS task force guidelines of screening every other year. In addition to patient compliance, communication is essential for patients and providers to each understand how the other perceives cancer, its prevention and treatment. By establishing a mutual understanding, physicians and their patients can work together to improve cancer screening rates ${ }^{21}$. Third, factors that affect patient decisionmaking such as education were not surveyed. Patients who do not understand the health care system are less likely to get screened for cancer. Research on disease stage at the time of diagnosis, rates of breast-conserving surgery or other treatments, and breast cancer survival rates have demonstrated that race effects decrease or disappear after stratifying based on education ${ }^{5}$. Our results are representative in what has been reported in the literature thus far in terms of disparate treatment due to factors that affect access to care such as socioeconomic profiles and patient and center barriers.

\section{Conclusion}

Despite implementation of a PNP, many factors contribute to disparate treatment in breast cancer screening. The mere presence of a barrier to obtain breast cancer screening revealed that women from the lowest income quartiles have prolonged screening times regardless of center or barrier presence or type. Low SES and minority women tend to have less access when compared to high SES women and experience disparate treatment. Our study underscores the need for continued efforts focused on mitigating the barriers and healthcare system challenges that minority and low-income women face in breast cancer care. In particular, efforts should focus on increasing social support for women who experience fear as a major obstacle to breast cancer screening completion, as well as a financial boost for patient transportation and childcare services at medical centers. It is essential that we strive to make improvements in health care navigation and delivery for low SES women in order to improve access to care and ultimately outcomes. Further, resource allocation to overburdened safety-net hospitals remains paramount for timely care and preventative screening. Healthcare practitioners and policy makers must be aware of the aforementioned intrinsic differences between city and county populations in order to address disparate care.

\section{Declarations}

Ethical approval and informed consent: The study was approved by and carried out in accordance with the Institutional Review Board of the New York Medical College and Westchester Medical Center (\#L-12,953). The informed consent was waived by ethics committee of New York Medical College.

Consent for publication: not applicable, as no identifying data is used in the study

Availability of data and materials: The datasets used and analyzed during the current study are available from the corresponding author on reasonable request.

Competing interests- none

Funding: none

Author contributions:

Study conception and design: Castaldi

Acquisition of data: Castaldi, Smiley

Page $9 / 11$ 
Analysis and interpretation of data: Castaldi, Smiley, Kechejian, Butler

Drafting of manuscript: Castaldi, Kechejian, Smiley

Critical revision: Castaldi, Latifi

Acknowledgements-Not applicable

\section{References}

1. Affordable Care Act State-Specific Medicaid Expansion: Impact on Health Insurance Coverage and Breast Cancer Screening Rate- Clinical Key. Accessed June 29, 2020. https://www.clinicalkey.com/\#!/content/playContent/1-s2.0-S1072751520302131? returnurl=null\&referrer=null

2. Maria Castaldi, Abbas Smiley, Jonathan Butler, Rifat Latifi. Breast Cancer Screening in Inner City and County Populations: A Tale of Two Centers. The American Surgeon. July 24, 2020. Epub ahead of print.

3. Get Screened, No Excuses. Welcome to the State of New York. Published December 31, 2015. Accessed August 16, 2020. https://www.ny.gov/GetScreened

4. Governor Cuomo Announces $\$ 37.7$ Million Awarded to Improve Access to Breast Cancer Screening Across New York State. Governor Andrew M. Cuomo. Published February 1, 2018. Accessed September 27, 2020.

https://www.governor.ny.gov/news/governor-cuomo-announces-377-million-awarded-improve-access-breast-cancer-screeningacross-new

5. Equitable access to cancer services - Mandelblatt - 1999 - Cancer - Wiley Online Library. Accessed June 19, 2020.

https://acsjournals.onlinelibrary.wiley.com/doi/10.1002/\%28SICI\%291097-

0142\%2819991201\%2986\%3A11\%3C2378\%3A\%3AAID-CNCR28\%3E3.0.CO\%3B2-L

6. Barriers to follow-up of abnormal screening mammograms among low-income minority women. Ethnicity \& Health. 1996;1(3):221. doi:10.1080/13557858.1996.9961790

7. Sutton JP, Washington RE, Fingar KR, Elixhauser A. Characteristics of Safety-Net Hospitals, 2014: Statistical Brief \#213. In: Healthcare Cost and Utilization Project (HCUP) Statistical Briefs. Agency for Healthcare Research and Quality (US); 2006. Accessed July 1, 2020. http://www.ncbi.nlm.nih.gov/books/NBK401306/

8. (PDF) Comparison of Change in Quality of Care Between Safety-Net and Non Safety-Net Hospitals. Accessed July 2, 2020. https://www.researchgate.net/publication/5373336_Comparison_of_Change_in_Quality_of_Care_Between_SafetyNet_and_Non_Safety-Net_Hospitals

9. Safety-Net and Non-Safety-Net Hospitals Deliver Similar PCI Outcomes - American College of Cardiology. Accessed July 2, 2020. https://www.acc.org/about-acc/press-releases/2017/08/07/13/46/safety-net-and-non-safety-net-hospitals-deliver-similar-pcioutcomes

10. Bickell NA, Moss AD, Castaldi M, et al. Organizational Factors Affect Safety-Net Hospitals' Breast Cancer Treatment Rates. Health Services Research. 2017;52(6):2137-

11. Effect of hospital safety net designation on treatment use and survival in hepatocellular carcinoma - Mokdad - 2018 - Cancer Wiley Online Library. Accessed July 3, 2020. https://acsjournals.onlinelibrary.wiley.com/doi/full/10.1002/cncr.31066

12. Jaiswal K, Hull M, Furniss AL, Doyle R, Gayou N, Bayliss E. Delays in Diagnosis and Treatment of Breast Cancer: A Safety-Net Population Profile. Journal of the National Comprehensive Cancer Network. 2018;16(12):1451-1457. doi:10.6004/jnccn.2018.7067

13. Bilimoria KY, Ko CY, Tomlinson JS, et al. Wait Times for Cancer Surgery in the United States: Trends and Predictors of Delays. Annals of Surgery. 2011;253(4):779-785. doi:10.1097/SLA.0b013e318211cc0f

14. "Perfecting Patient Flow: America's Safety Net Hospitals and Emergency " by Marcia J. Wilson, Bruce Siegel et al. Accessed July 3, 2020. https://hsrc.himmelfarb.gwu.edu/sphhs_policy_facpubs/223/

15. Akinyemiju TF, Genkinger JM, Farhat M, Wilson A, Gary-Webb TL, Tehranifar P. Residential environment and breast cancer incidence and mortality: a systematic review and meta-analysis. BMC Cancer. 2015;15(1). Accessed July 1, 2020. https://link.gale.com/apps/doc/A541402348/HRCA?u=nysI_me_nymcv\&sid=zotero\&xid=2f529160 
16. Elkin EB, Ishill NM, Snow JG, et al. Geographic Access and the Use of Screening Mammography. Med Care. 2010;48(4):349-356. doi:10.1097/MLR.0b013e3181ca3ecb

17. Reims KG. HRSA CCM: Breast Cancer Screening. Breast Cancer Screening::51.

18. Demographic and economic trends in urban, suburban and rural communities. Pew Research Center's Social \& Demographic Trends Project. Published May 22, 2018. Accessed June 24, 2020. https://www.pewsocialtrends.org/2018/05/22/demographicand-economic-trends-in-urban-suburban-and-rural-communities/

19. City-dwellers Have Higher Risk Of Late-stage Cancer Than Rural Residents. ScienceDaily. Accessed July 1, 2020. https://www.sciencedaily.com/releases/2009/05/090511090844.htm

20. Gorin SS, Heck JE, Cheng B, Smith SJ. Delays in Breast Cancer Diagnosis and Treatment by Racial/Ethnic Group. Arch Intern Med. 2006;166(20):2244-2252. doi:10.1001/archinte.166.20.2244

21. Gregg J, Curry RH. Explanatory models for cancer among African-American women at two Atlanta neighborhood health centers: the implications for a cancer screening program. Soc Sci Med. 1994;39(4):519-526. doi:10.1016/0277-9536(94)90094-9

22. Davis TC, Arnold CL, Rademaker A, et al. Differences in Barriers to Mammography Between Rural and Urban Women. J Womens Health (Larchmt). 2012;21(7):748-755. doi:10.1089/jwh.2011.3397

23. DrPH DLW, PhD ST, PhD JT. Factors Associated with Delays to Diagnosis and Treatment of Breast Cancer in Women in a Louisiana Urban Safety Net Hospital. Women \& Health. 2010;50(8):705-718. doi:10.1080/03630242.2010.530928

24. Disparities in Health Care Are Driven by Where Minority Patients Seek Care: Examination of the Hospital Quality Alliance Measures | Acute Coronary Syndromes | JAMA Internal Medicine | JAMA Network. Accessed July 2, 2020. https://jamanetwork.com/journals/jamainternalmedicine/fullarticle/412653

25. Lopez L, Jha AK. Outcomes for whites and blacks at hospitals that disproportionately care for black Medicare beneficiaries. Health Services Research. 2013;48(1):114-.

26. Miller JW, Hanson V, Johnson GD, Royalty JE, Richardson LC. From cancer screening to treatment: Service delivery and referral in the National Breast and Cervical Cancer Early Detection Program. Cancer. 2014;120(S16):2549-2556. doi:10.1002/cncr.28823

27. Alexandraki I, Mooradian AD. Barriers Related to Mammography Use for Breast Cancer Screening Among Minority Women. Journal of the National Medical Association. 2010;102(3):206-218. doi:10.1016/S0027-9684(15)30527-7

28. Reducing Structural Barriers | ScreenOutCancer | CDC. Accessed July 31, 2020. https://www.cdc.gov/screenoutcancer/interventions/reducing-structural-barriers.htm

29. Fayanju OM, Kraenzle S, Drake BF, Oka M, Goodman MS. Perceived Barriers to Mammography among Underserved Women in a Breast Health Center Outreach Program. Am J Surg. 2014;208(3):425-434. doi:10.1016/j.amjsurg.2014.03.005

30. Garbers S, Jessop DJ, Foti H, Uribelarrea M, Chiasson MA. Barriers to breast cancer screening for low-income Mexican and Dominican women in New York City. J Urban Health. 2003;80(1):81-91. doi:10.1007/pl00022327

31. Castaldi M, Safadjou S, Elrafei T, McNelis J. A Multidisciplinary Patient Navigation Program Improves Compliance With Adjuvant Breast Cancer Therapy in a Public Hospital. Am J Med Qual. 2017;32(4):406-413. doi:10.1177/1062860616656250

\section{Appendix}

No appendix file was provided with the journal submission 